\title{
Enabling Guidelines for the Adoption of eHealth Solutions: Scoping Review
}

Linn Nathalie Støme, MSc, PhD; Christian Ringnes Wilhelmsen, MSc; Kari Jorunn Kværner, MD, PhD, Prof Dr

Centre for Connected Care, Oslo University Hospital, Oslo, Norway

Corresponding Author:

Linn Nathalie Støme, MSc, PhD

Centre for Connected Care

Oslo University Hospital

Kirkeveien 166

Oslo

Norway

Phone: 4794880825

Email: $\underline{\text { linast@ous-hf.no }}$

\section{Abstract}

Background: Globally, public health care is under increasing pressure, an economic burden currently amplified by the COVID-19 outbreak. With the recognition that universal health coverage improves the health of a population and reduces health inequalities, universal health coverage has been acknowledged as a priority goal. To meet the global needs in a population with increased chronic illness and longer life expectancy, the health care system is in dire need of new, emerging technologies. eHealth solutions as a method of delivery may have an impact on quality of care and health care costs. As such, it is important to study methods previously used to avoid suboptimal implementation and promote general guidelines to further develop eHealth solutions.

Objective: This study aims to explore and thematically categorize a selected representation of early phase studies on eHealth technologies, focusing on papers that are under development or undergoing testing. Further, we want to assess enablers and barriers in terms of usability, scaling, and data management of eHealth implementation. The aim of this study to explore early development phase and feasibility studies was an intentional effort to provide applicable guidelines for evaluation at different stages of implementation.

Methods: A structured search was performed in PubMed, MEDLINE, and Cochrane to identify and provide insight in current eHealth technology and methodology under development and gain insight in the future potential of eHealth technologies.

Results: In total, 27 articles were included in this review. The clinical studies were categorized thematically by illness comparing 4 technology types deemed relevant: apps/web-based technology, sensor technology, virtual reality, and television. All eHealth assessment and implementation studies were categorized by their focus point: usability, scaling, or data management. Studies assessing the effect of eHealth were divided into feasibility studies, qualitative studies, and heuristic assessments. Studies focusing on usability (16/27) mainly addressed user involvement and learning curve in the adoption of eHealth, while the majority of scaling studies (6/27) focused on strategic and organizational aspects of upscaling eHealth solutions. Studies focusing on data management (5/27) addressed data processing and data sensitivity in adoption and diffusion of eHealth. Efficient processing of data in a secure manner, as well as user involvement and feedback, both throughout small studies and during upscaling, were the important enablers considered for successful implementation of eHealth.

Conclusions: eHealth interventions have considerable potential to improve lifestyle changes and adherence to treatment recommendations. To promote efficient implementation and scaling, user involvement to promote user-friendliness, secure and adaptable data management, and strategical considerations needs to be addressed early in the development process. eHealth should be assessed during its development into health services. The wide variation in interventions and methodology makes comparison of the results challenging and calls for standardization of methods.

(JMIR Form Res 2021;5(4):e21357) doi: 10.2196/21357

\section{KEYWORDS}

eHealth; feasibility; global health; implementation 


\section{Introduction}

Health care constitutes a significant part of public sector expenditure. Total government expenditures among Organisation for Economic Co-operation and Development countries was $41 \%$ of the gross domestic product in 2015 , and health typically accounts for around $20 \%$ of these expenditures [1]. There are several factors hindering efficient improvements in health care services across the globe; one of them is failure to adopt eHealth solutions [2]. With the recognition that universal health coverage improves the health of a population and reduces health inequalities, universal health coverage has been acknowledged as a priority goal of many health systems [3]. As such, the Commission on Social Determinants of Health emphasizes the importance of closing global and national health gaps through enhanced access to a high-quality and safe health supply [3]. As early as 1948, the United Nations declared enhanced access to a high-quality and safe health supply a priority goal [4]. To get around the logistical issues of delivering and receiving health care, both doctors and patients rely on digital communication channels to inform patients and enhance self-management.

Health interventions delivered suboptimally may reduce effective coverage [5]. Although life expectancy has increased globally following the United Nations declaration, the pace of improvement has been slowing down leaving behind large parts of the world's population [6,7]. To achieve the ambitious task of universal health coverage by 2030 as postulated by the World Health Organization and World Bank, radical changes in social and economic trends are necessary [6,7], including improving daily living conditions; addressing inequitable distribution of power, money, and resources; and assessing the impact of action needed [8]. Successful implementation of eHealth solutions requires altering existing health care practices and therefore represents such an opportunity. New approaches delivered by eHealth solutions have the ability to enhance access and quality of care and reduce health care costs [9].

Digitalization, the process of transforming an organization into a digital form, may be considered a driving force in changing health care delivery and may improve accessibility globally [10]. In order to provide equal access to treatment of noncommunicable diseases, which represents the greatest health burden, the possibilities found within digitalization may be substantial [11]. Further, increase in life expectancy is expected to present an influx of patients health care systems are not equipped for. These patients commonly present with complex long-term needs requiring continuity of care, long-term hospitalization, and increased need for individualized care [12]. In addition, the recent COVID-19 pandemic has proved the importance of increased access to care while reducing risk of cross-contamination [13]. As such, several eHealth solutions have been rapidly put into use without a timeframe for tailored implementation or evaluation [14]. For health interventions to maximize benefit, they need to increase service quality and address the imminent needs of the target subpopulation: patients, health providers, and administrators [15].

A high-quality health service can only be achieved if patient outcomes and costs of delivery are addressed [16]. When considering complex health care systems, there are many areas of interest, including legal, organizational, economic, and social aspects, and each needs to be taken into account when looking to implement new technologies [17]. Within these areas, usability of product, learning curve for users, and the need for a recognized standard for patient data security have been highlighted as critical factors in eHealth implementation and scaling $[18,19]$. Adoption and diffusion of eHealth solutions may be time-consuming and require significant adaptation of work practices [20], and the development and rigorous evaluation of new models of care has been requested [21]. Research has found a discrepancy between the expected value of eHealth and mobile health interventions and the empirically demonstrated benefits [22,23].

In addition to evaluation of eHealth technologies, selection of correct implementation and scaling procedure should be prioritized. Varsi et al [24] found in a review of implementation strategies for eHealth that little attention has been paid to reporting implementation strategies for eHealth and that the feasibility may be compromised as the integration may be perceived as an interruption to existing patient workloads. Implementation processes may be complex as they may concern multilevel organizational structures and involve a wide range of health care stakeholders. A mixed method approach of assessment may be useful when preparing the health care sector for implementation. Applying quantitative methods to explore relationships between digital solutions and disease outcomes may prove useful in enhancing quality of care [25]. In addition, qualitative methods may provide a deeper understanding of contextual factors influencing these relationships and offer information on enablers and barriers to technological implementation globally [26]. This allows for iterative modifications and adaptations from the initial development phase to avoid implementation and scaling of ineffective services. To promote implementation of eHealth solutions with the greatest value to patients, the health care system, and society, we should look at potential value from the very start of the development cycle and throughout testing and implementation [27]. One challenge, however, is that early stages of innovation may suffer from lack of valid data sources.

This study aims to explore and thematically categorize a selected representation of early phase studies on eHealth technologies, focusing on papers that are under development or undergoing testing and assess the studies for common enablers and barriers of eHealth implementation. In summary, through exploring early development phase and feasibility studies we aim to provide applicable guidelines for evaluation throughout the stages of implementation.

\section{Methods}

\section{Reporting Standards}

The review was structured according to PRISMA (Preferred Reporting Items for Systematic Reviews and Meta-analyses) guidelines [28]. 


\section{Selection Criteria}

Through two consecutive screenings, we reviewed the articles applying these inclusion criteria: (1) articles reporting some form of early stage eHealth solution (articles were excluded if the intervention or innovation did not consist of eHealth solutions) and (2) articles presenting particular focus on mixed methods to evaluate the feasibility of eHealth (articles were excluded if they did not evaluate the feasibility of eHealth solutions). Detailed inclusion and exclusion criteria can be seen in Textbox 1.

Textbox 1. Selection criteria.

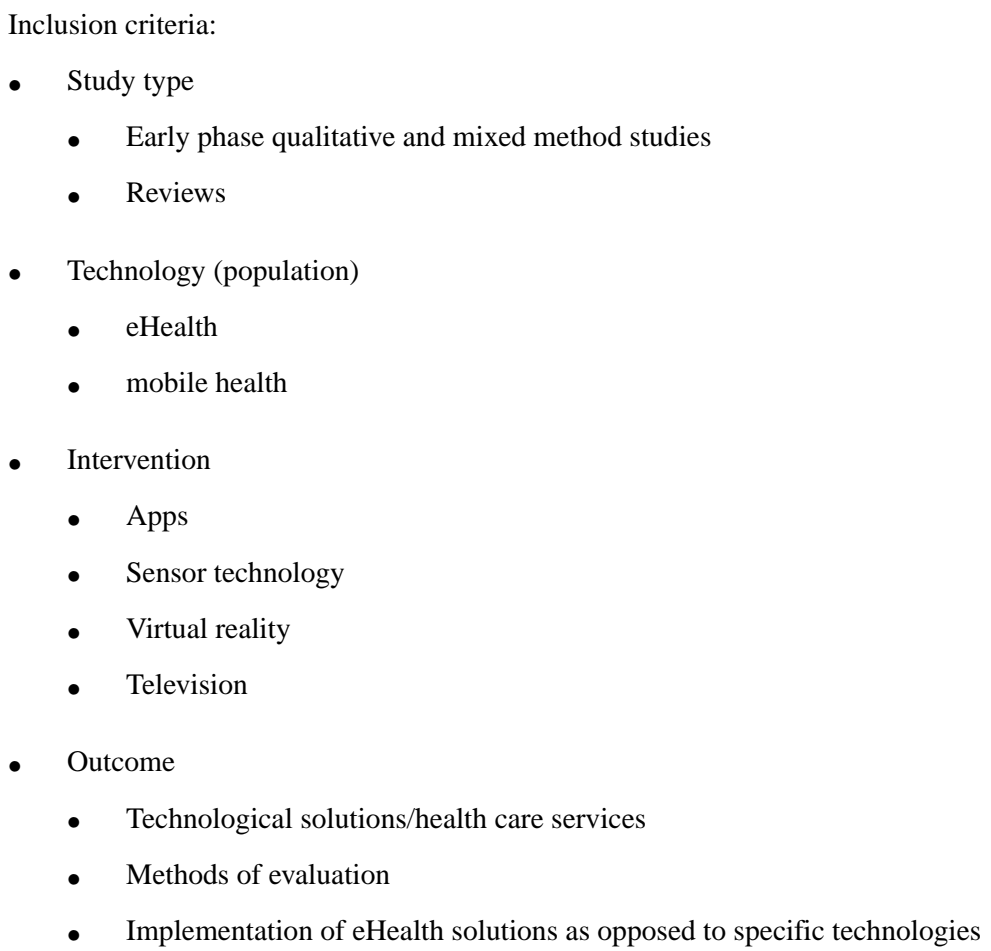

Exclusion criteria:

- Study type

- Language not in English, Norwegian, or Danish

- Purely quantitative research

- $\quad$ Published prior to 2008

- Technology (population)

- No digital innovations

- Articles deemed not innovative enough

- Intervention

- $\quad$ Short message (texting) services

- Interventions not containing digital innovation

- Outcome

- Articles not falling into categories stated in the inclusion criteria

\section{Outcome Measures}

This study aims to explore eHealth technologies under development or undergoing testing to identify enablers and barriers to implementation. We used thematic analysis to categorize the studies according to a preselected thematic framework comprising the following categories: user, technology, analysis, country of origin, and focus point.

\section{Search Strategy}

A literature search was conducted in April 2019 using PubMed, Ovid MEDLINE, and Cochrane. The specifics of the search were constructed and performed with the assistance of a librarian 
with experience in systematic search methods. The search was done using a variety of text words and subject headings. The search strategy for MEDLINE was built using the MeSH terms "telemedicine," "home care services," "self-help devices," "communication aids for disabled," "information technology," "biomedical technology," or "telenursing" and synonyms and near-synonyms thereof combined with the text words "technology assessment, biomedical." The full search strategy can be found in Multimedia Appendix 1.

\section{Selection of Studies}

Textbox 1 shows the final inclusion and exclusion criteria agreed upon by the review group. Due to the high number of articles found through the initial search, certain parts of the inclusion criteria were added during the elimination process, mainly in the Intervention category. In addition, we excluded papers published before 2008 partly due to relevance but also to decrease the number of articles. References from each database search were imported into database-specific folders in EndNote (version X9, Clarivate Analytics), and duplicates were eliminated. Abstracts were first assessed by CRW using the selection criteria listed in Textbox 1 , and then each of the full-text articles was appraised independently by two reviewers (CRW and LNS). Disagreements were resolved by discussion or by referring to a third author (KJK).

The topic of eHealth solutions is rather broad, and it is challenging to ensure inclusion of all relevant papers within this topic. In an effort to thematically analyze the included studies, the studies were initially thematically categorized in disease groups that represent a great health burden and cost for society, including cardiovascular diseases, cancer, diabetes, and chronic lung disease, as they make the largest contribution to morbidity and mortality [29]. Regarding technology, we focused on commonly used eHealth solutions. However, as the aim of this scoping review was to study barriers and enablers of eHealth implementation, some studies were included as they either focused on specific barriers or enablers of eHealth implementation or evaluated promising technologies less widespread.

The data were extracted by CRW and discussed with LNS. During this process, a framework based on the assessed literature was agreed upon and core themes to answer the research issue were identified. When there was a disagreement among the authors on the appropriate theme, the article was discussed until agreement was achieved. Bibliographic data and study content were collected and analyzed using templates developed iteratively with feedback from the other authors (KJK and LNS).

\section{Data Synthesis and Analyses}

Data from the included studies were categorized in Table 1 to provide an overview of the study characteristics for further assessment. Through this categorization and subsequent analysis, we aimed to study barriers and enablers to eHealth implementation.

The data extracted from the included studies were categorized based on Støme et al [30] as follows:
User: Data were categorized by user group targeted by the study: chronic obstructive pulmonary disease (COPD)/asthma, cardiovascular disease, diabetes, elderly adults, and other/not specified.

Technology: Studies were categorized as clinical if a specific technology was applied and divided into four subgroups: apps/web-based technology, sensor technology, virtual reality, and television. Studies were categorized as theoretical if eHealth implementation issues were addressed and divided into the subgroups usability, scaling, and data management.

Analysis: Identified articles were characterized by strategic, economic, and clinical analysis based on the purpose of the analysis and not the analytical approach used, as one analytical approach can be used for different purposes.

Country: Original articles were categorized by country of origin. Reviews were categorized by country of publication or origin of authors. Case studies were categorized by country where study took place.

Focus point: Studies addressing eHealth assessment and implementation were categorized by usability, scaling and data management.

\section{Results}

\section{Study Selection}

An initial search identified 18,613 studies, and reviewers performed a rough quality assessment by searching through EndNote for the terms "eHealth," "implementation," "feasibility," "early phase" to explore and thematically categorize early phase studies on eHealth technologies under development or undergoing testing. The coarseness of this method was deemed necessary due to the large amount of papers following the initial search. The primary search also included home-hospital services, which did not include eHealth solutions. In the selection of relevant studies for this scoping review, we therefore excluded a large number of studies of moving care to the patients' home without the use of digitalization or eHealth solutions. Following this method, 628 papers remained. To further narrow the scope, CRW assessed the abstract texts for relevance to the topic, including studies on early phase eHealth development and adoption. Papers published prior to 2008 were excluded as we deemed this to be a suitable breakpoint for technological progress, and articles published prior to this year could have been outdated. Due to the rapid progression of technology development, at a certain point eHealth solutions become outdated when new technology enters the market. Although 2008 is not a year specific for such change, we deemed it adequate to avoid evaluating outdated technology. Following the second assessment, 81 articles remained.

The studies were rigorously assessed, entered on a spreadsheet, and given a general rating based on study design and points of analysis. Relevant stakeholders, advantages of the approach, current research phase, and situational value of the technology were also considered. A focus on variance between papers to gain a holistic view of the topic was an underlying factor for selection. Following this assessment, 27 reviews, pilot studies, 
and other forms of research papers were chosen as the basis for this review. The underlying intention behind this review was to identify works of literature and articles addressing both methodological approaches and eHealth solutions in their early phase/concept development/pilot studies. Black et al [22] observed a gap in methodological approaches to studying the empirical evidence concerning the effect of eHealth interventions. Through our search it became apparent that few articles capture implementation and assessment of eHealth. The papers in our review focus on technologies used to treat chronic conditions. An overview of the study selection is shown in Figure 1.

Figure 1. Flow diagram for studies included in the review.

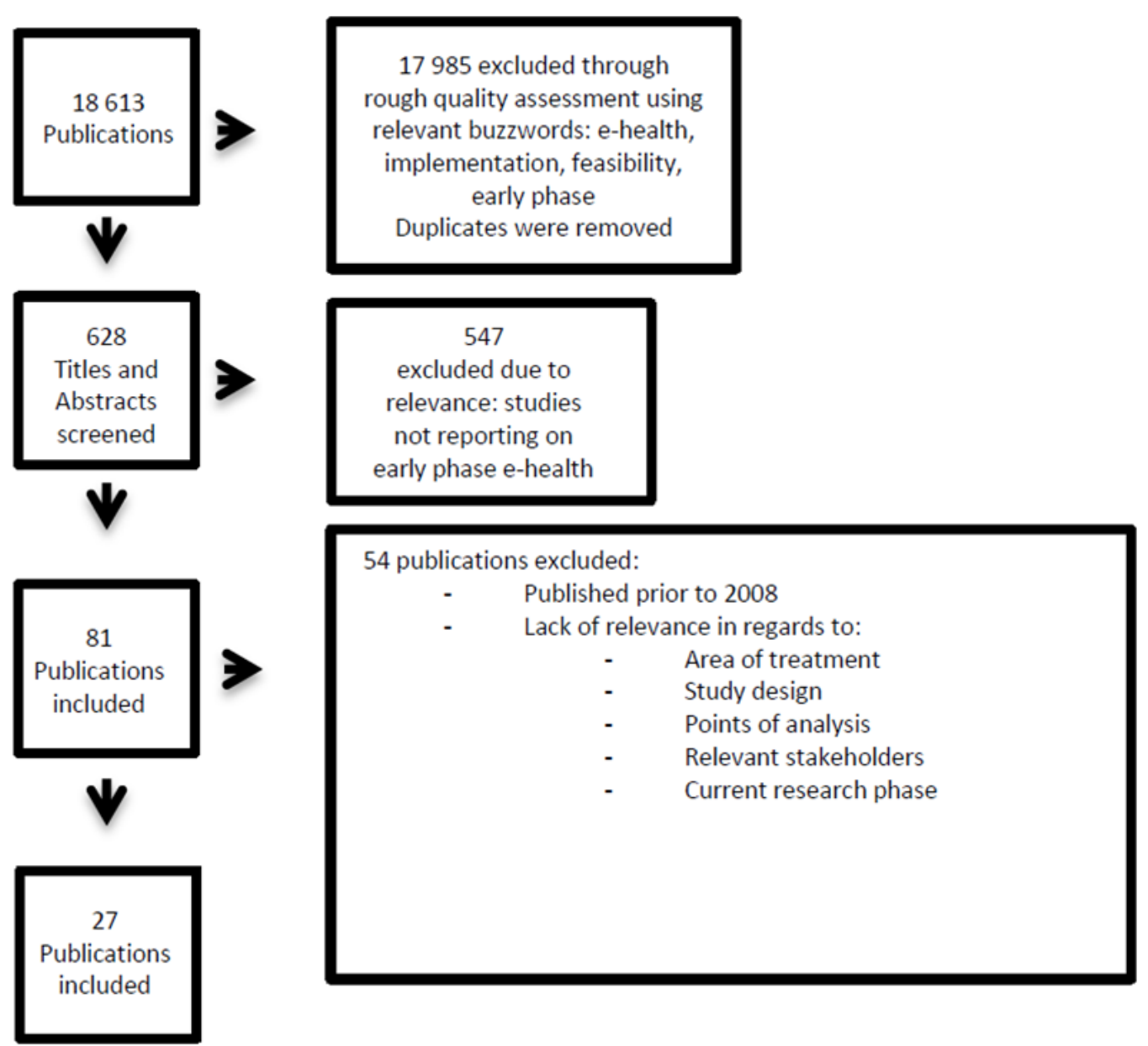

\section{Study Characteristics}

The studies selected to undergo a thorough evaluation are shown in Table 1. Enablers and barriers of eHealth implementations will be discussed further in light of findings from these studies. Based on their main focus point, the studies were divided into the categories usability, scaling, or data management. Studies focusing on usability (16/27) mainly addressed user involvement and learning curve in the adoption of eHealth, while the scaling studies (6/27) focused on strategic and organizational aspects of upscaling eHealth solutions. Studies focusing on data management $(5 / 27)$ addressed data processing sets and data sensitivity in adoption and diffusion of eHealth.

The studies were thematically analyzed and sorted into 5 categories based on illness, although some degree of overlap was found in some studies: patients with COPD/asthma (6/27) [31-35], patients with cardiovascular disease (3/27) [36-38], patients with diabetes $(2 / 27)$ [39,40], and elderly patients $(8 / 27)$ [41-48]. While the majority of apps/web-based technology had disease-specific targets, the other technologies were used more frequently with elderly patients. The remaining 8 studies were categorized as other or nonspecified, as illness was not described [49-55] or they focused on issues more relevant from an organizational or caregivers point of view [56,57]. These studies provided theoretical insight into how a given technology may assist in remote treatment and care [49-57].

The majority of the studies were from western countries: 10 studies originated from the United States [33,37,39,44,47-49,51,56,57], 3 from Australia [31,41,55], 4 from England [32,36,45,53], and 3 from Italy [42,43,46]. The remaining 7 studies each took place in Belgium [40], Denmark [35], Japan [34], Malaysia [53], Netherlands [38], Switzerland [54], and Norway [50], respectively. 
Table 1. Description of the data and data analysis.

\begin{tabular}{|c|c|c|c|c|c|}
\hline Author (year) & User & Technology & Focus point & Analysis & Country \\
\hline Abd Sukor et al (2015) [41] & Elderly adults & Data algorithm & $\begin{array}{l}\text { Data manage- } \\
\text { ment }\end{array}$ & Clinical analysis & Australia \\
\hline Aguilar et al (2014) [49] & Not specified & Multifaceted & Scaling & Strategic analysis & $\mathrm{US}^{\mathrm{a}}$ \\
\hline Angius et al (2008) [42] & Elderly adults & Television & Usability & Strategic/economic analysis & Italy \\
\hline Arlati et al (2019) [43] & Elderly adults & Virtual reality & Usability & Strategic analysis & Italy \\
\hline Bartels et al (2017) [44] & Elderly adults & Multifaceted & Scaling & Strategic analysis & US \\
\hline Burkow et al (2008) [50] & $\begin{array}{l}\text { Unspecified chronic } \\
\text { disease }\end{array}$ & Television & Usability & Strategic analysis & Norway \\
\hline Burrige et al (2017) [36] & Cardiovascular disease & Sensor technology & Usability & Clinical/strategic analysis & England \\
\hline Cai et al (2015) [45] & Elderly adults & Sensor technology & Usability & Strategic analysis & England \\
\hline Chi and Demiris (2015) [56] & $\begin{array}{l}\text { Chronic disease pa- } \\
\text { tients' caregivers }\end{array}$ & Multifaceted & Usability & Strategic analysis & Primarily US \\
\hline Ding et al (2012) [31] & $\mathrm{COPD}^{\mathrm{b}}$ & App and web portal & $\begin{array}{l}\text { Data manage- } \\
\text { ment }\end{array}$ & Clinical/strategic analysis & Australia \\
\hline Fitzsimmons et al (2016) [32] & COPD & Sensor technology & Usability & Strategic analysis & England \\
\hline Georgsson and Staggers (2017) [39] & Diabetes & App and web portal & Scaling & Strategic analysis & US \\
\hline Hui et al (2017) [33] & COPD & App & Usability & Clinical analysis & US \\
\hline Kamei et al (2012) [34] & COPD & Sensor technology & Usability & Economic/clinical analysis & Japan \\
\hline Kitsiou et al (2015) [37] & Cardiovascular disease & Multifaceted & Scaling & Strategic analysis & US \\
\hline Lilhot et al (2015) [35] & COPD & $\begin{array}{l}\text { Web-based and tablet } \\
\text { technology }\end{array}$ & Usability & Strategic analysis & Denmark \\
\hline Mantas et al (2009) [57] & Data security & $\begin{array}{l}\text { Data processing algo- } \\
\text { rithm }\end{array}$ & $\begin{array}{l}\text { Data manage- } \\
\text { ment }\end{array}$ & Strategic analysis & US \\
\hline McLean et al (2013) [51] & Not specified & Multifaceted & Scaling & Clinical/economic analysis & US \\
\hline Monkman (2015) [38] & Cardiovascular disease & App & Usability & Strategic analysis & Netherlands \\
\hline Mora et al (2018) [46] & Elderly adults & Sensor technology & $\begin{array}{l}\text { Data manage- } \\
\text { ment }\end{array}$ & Strategic analysis & Italy \\
\hline Norman et al (2018) [47] & Elderly adults & Multifaceted & Usability & Strategic analysis & US \\
\hline Sanders et al (2012) [52] & Not specified & Multifaceted & Usability & Strategic analysis & England \\
\hline Simon and Seldon (2012) [53] & Not specified & $\begin{array}{l}\text { App and sensor tech- } \\
\text { nology }\end{array}$ & $\begin{array}{l}\text { Data manage- } \\
\text { ment }\end{array}$ & Strategic analysis & Malaysia \\
\hline Tschanz et al (2017) [54] & Not specified & App & Usability & Strategic analysis & Switzerland \\
\hline Hoecke et al (2010) [40] & Diabetes & App & Usability & Strategic analysis & Belgium \\
\hline Wade et al (2016) [55] & Not specified & Multifaceted & Scaling & Strategic analysis & Australia \\
\hline Weiner et al (2016) [48] & Elderly adults & Virtual reality & Usability & Strategic analysis & US \\
\hline
\end{tabular}

${ }^{\mathrm{a}}$ US: United States.

${ }^{\mathrm{b}} \mathrm{COPD}$ : chronic obstructive pulmonary disease.

\section{Intervention Characteristics}

The characteristics of the interventions by technology and illness are summarized in Table 2. The categories were determined following the selection of studies, in an attempt to categorize the studies. The studies were divided into 5 categories based on the type of platform they used, although overlap between technologies was shown in some studies. Among the clinical studies, 8 presented apps combined with web-based technology as their intervention $[31,33,35,38-40,53,54]$. This was the most common study technology, mainly applied in patients with COPD and asthma. Five studies used sensor intervention, located on the human body or placed indoors in the patients' home $[32,34,36,45,46]$. Two studies used virtual reality as a method of intervention $[43,48]$; in the remaining 2 , television was tested as a suitable technology [42,50].

Ten studies were categorized theoretical as they did not present a particular technology but focused on general remote care issues $[37,41,44,47,49,51,52,55-57]$. The studies were placed 
in one of the 3 subcategories: usability [47,52,56], scaling $[37,44,49,51,55]$, and data management $[41,57]$, depending on their primary point of focus. Of these, the majority had communication between patient and practitioner as their primary goal.

Table 2. Study categorization.

\begin{tabular}{|c|c|c|c|c|c|c|c|c|}
\hline \multirow[t]{2}{*}{ Technology/remote care issues } & \multicolumn{3}{|l|}{ Clinical studies } & & \multicolumn{3}{|c|}{ Theoretical studies } & \multirow[t]{2}{*}{ Total } \\
\hline & $\begin{array}{l}\text { Apps/web-based } \\
\text { technology }\end{array}$ & Sensor technology & Virtual reality & Television & Usability & Scaling & $\begin{array}{l}\text { Data manage- } \\
\text { ment }\end{array}$ & \\
\hline $\mathrm{COPD}^{\mathrm{a}}$ /asthma & 4 & 2 & $-{ }^{b}$ & - & - & - & - & 6 \\
\hline Cardiovascular disease & 1 & 1 & - & - & - & 1 & - & 3 \\
\hline Diabetes & 2 & - & - & - & - & - & - & 2 \\
\hline Elderly adults & - & 2 & 2 & 1 & 1 & 1 & 1 & 8 \\
\hline Other/not specified & 1 & - & - & 1 & 2 & 3 & 1 & 8 \\
\hline Total & 8 & 5 & 2 & 2 & 3 & 5 & 2 & 27 \\
\hline
\end{tabular}

${ }^{\mathrm{a}}$ COPD: chronic obstructive pulmonary disease.

${ }^{\mathrm{b}}$ Not applicable.

\section{Assessment of eHealth Solutions}

Early assessment of the potential effect of eHealth solutions was studied in this scoping review with the aim of providing guidelines for evaluation at different stages of implementation. Feasibility can be assessed through qualitative and quantitative methods and may reflect strategic analysis to prepare for implementation or show clinical and safety aspects of the care provided. The feasibility of eHealth interventions was assessed in 6 studies [31,36,41,43,46,50] applying acceptability, usability, and/or utility data from the intervention. Qualitative assessments of the effects of eHealth solutions were also found in this review [32,39,45,47,48,52,54,55]. A Cochrane review [58] identified the need for additional qualitative research to determine if and why particular eHealth interventions are effective. Fitzsimmons et al [32] observed a need to integrate patient satisfaction measures based on patient perceptions of the eHealth technology.

In this review, 2 studies reported on heuristic approaches to evaluation of eHealth solutions [35,38]. These studies emphasized the need to enhance usability in the development and testing of new eHealth solutions. Usability is the extent to which a product or service may be used by a cohort of users to achieve effectiveness, efficacy, and satisfaction in a specified context of use [59]. This may be enhanced by studying users and behavioral data collected during the development of technologies [32]. Such assessments may be time-consuming and resource demanding. Heuristic methods represent a timelier and less expensive approach to assess usability, as user friendliness may be a requirement to achieve full benefit from eHealth solutions in terms of clinical outcomes and patient satisfaction [35].

\section{Discussion}

\section{Principal Findings or Summary}

This scoping review identified apps/web-based technology and sensor technology as commonly used thematic technologies.
Virtual reality, while not as commonly used within eHealth solutions, showed promising results in the studies identified and was included in this study in part due to its wide potential. Television was also found to be used to a somewhat lesser extent, but we included it in this paper due to ease-of-use and high accessibility across patient groups. Within the representative studies assessed in this study, apps/web-based technology had disease-specific targets, while the other technologies were primarily used in elderly patients, where the desire for individualized and tailored care is high [60]. Through analyzing the studies, we identified usability, scaling, and data management as important research areas regardless of eHealth implementation. Studies focusing on usability mainly addressed user involvement and learning curve in the adoption of eHealth, while the majority of scaling studies focused on strategic and organizational aspects of upscaling eHealth solutions. Studies focusing on data management addressed data processing and data sensitivity in adoption and diffusion of eHealth. To explore factors critical for implementation of eHealth based on the studies included in this review, data security and processing, user involvement and feedback, and transitioning from smallto large-scale implementation will be discussed below.

We found that although the emergence of eHealth technologies creates a plethora of innovation opportunities, it is apparent that proper guidelines for evaluating sufficient quality of product are currently not available. This may result in a lack of implementation of new technologies [26,40,43]. As the aim of this study was to explore early development phase and feasibility studies as an intentional effort to provide applicable guidelines for evaluation at different stages of implementation, contributions found in the literature are discussed in this section in the three focus areas: usability, scaling, and data management.

Today, people-centered health care is an increasing ambition [61], and health care is moving toward reduced hospital stays and emphasis on technology-driven solutions to support arena-flexible treatment strategies. Correspondingly, the engagement of end users has become a necessary component in the design and development of future health care [61]. 
Emphasis is on evidence and outcomes, and the participation of users in the provision of their own care has become essential [48]. User-centric design involving patients and health care providers can be employed from the earliest exploratory stages to help understand and design for the needs, goals, limitations, capabilities, and preferences of all stakeholders [62]. Technological development is constantly evolving, and continuous technological adoptions are challenging the identification of valid outcome measurements suitable for assessment of cost and patient benefits [63]. A potential solution may be to integrate an assessment of the whole development cycle, in order to help identify shortcomings and suboptimal parts/areas of innovations. The earlier stages of the development cycle, such as concept stages of innovation, may, however, suffer from lack of valid data sources. This may explain the heterogeneity in the evidence concerning the effect of eHealth interventions in the literature $[22,64,65]$.

\section{Data Management in the Integration of eHealth}

Efficient data transfer between parties without compromising the security of sensitive data is important to account for when integrating eHealth solutions. There are vast numbers of requirements for high-security protocols in eHealth. This is obviously due to the sensitive, and in some cases vital, nature of the data and should not be taken lightly [57]. Due to the large amount of data cryptically transferred from patients to practitioners and vice versa, suitable processing technology needs to be incorporated [41]. Especially in the cases of self-measurements, the amount of data is often vast and diluted with errors and noise artefacts since patients are often unaware of what they are supposed to look for [41]. Suitable systems for data processing should therefore be incorporated from an early phase to support the intent of lessening the workload through eHealth [41]. Only through implementing optimal security and processing programs into eHealth can an integrated approach to health care be achieved $[27,49]$. A summary of guidelines concerning data management in the integration of eHealth can be found in Table 3 .

Table 3. Summary of guidelines for eHealth implementation.

\begin{tabular}{lll}
\hline Guidelines & Reference & Summary \\
\hline Data management & {$[27,41,49,57]$} & $\begin{array}{l}\text { Efficient data transfer between parties without compromising the security of sensitive data. Only } \\
\text { through implementing optimal security and processing programs into eHealth can an integrated } \\
\text { approach to health care be achieved. }\end{array}$ \\
User adaptations & {$[29,32,39,44,45,66-68]$} & $\begin{array}{l}\text { User involvement may enhance usability and is a significant factor in the implementation of } \\
\text { eHealth. The need to account for patient and practitioner adherence was a common feature the } \\
\text { reviewed articles reported on. User training programs must provide such information to enhance } \\
\text { self-management and goal achievement. }\end{array}$ \\
Evaluation and scaling & $\begin{array}{l}\text { Four critical barriers affecting providers and patients in clinical implementation of eHealth are } \\
\text { reported: technological illiteracy and lack of knowledge, awareness, and access to the technology } \\
\text { itself. Early stage evaluations of eHealth may reveal hidden factors for successful implementation. } \\
\text { Integration of eHealth interventions must be seen as part of a service and not as a standalone } \\
\text { system. Two key actions for sustainable implementation are the marketing of eHealth to patients, } \\
\text { clinicians, and policymakers and establishing a practice community. }\end{array}$ \\
\hline
\end{tabular}

\section{User Adaptations to eHealth Solutions}

User involvement may enhance usability and is a significant factor in the implementation of eHealth [66-68]. In the articles reviewed that reported on patient and practitioner feedback, several key points were highlighted and should be accounted for whenever a technological innovation is evaluated. A common feature the reviewed articles reported on was the need to account for patient adherence $[29,39]$. However, the patients need to understand what to do, why they do it, and how the eHealth solution works to adhere to its use [44]. User training programs must provide such information to enhance self-management and goal achievement [39]. Rigorous training programs may be needed to facilitate successful self-management of the technology [39], as patients vary in understanding and personal motivation. Self-management helps patients gain a better understanding of their condition and enables better communication with their practitioners. This may also ease the intended transparency between patients and practitioners.

Rigorous training may not be enough to ensure uptake of eHealth solutions, and active user involvement in the design of eHealth solutions needs to be perceived as valuable for the participants, such as health care providers. To ensure successful implementation of eHealth, practitioner adherence is also required. Cai et al [45] reported that practitioners involved in the introduction of the technology gain a better sense of the value of the technology they are applying. Studies also highlight positive feedback from patients when the technology facilitates an interactive relationship between patient and practitioner, such as activity planning and communication with practitioners or other health care staff [32]. In this, however, it is increasingly important to uphold a robust level of data security and privacy [69], another factor to be thorough about throughout implementation of any technology [45]. A summary of guidelines concerning user adaptations of eHealth solutions can be found in Table 3 .

\section{Evaluation and Scaling of eHealth Solutions}

Successful implementation of eHealth solutions may require altering existing health care practices, which may influence patient-provider relationships. Four critical barriers affecting providers and patients in clinical implementation of eHealth are reported: technological illiteracy and lack of knowledge, awareness, and access to the technology itself [32,34]. As these 
barriers will vary greatly depending on social, geographical, and individual situations for patients and caregivers, innovators need to be aware of and make room for individualized alternatives within a given solution. In other words, optional customization within a given eHealth solution to account for each scenario should be included. Timely implementation of eHealth solutions is challenged by lack of early indications of patient benefits and costs. The purpose of this study was to explore how early assessment of eHealth solutions is communicated in the literature to study which markers of eHealth performance could be detected in an early phase. To ensure effective implementation and diffusion of eHealth solutions, each of these barriers needs to be addressed and assessed during the development process of the solution [36]. Early introduction and evaluation of the technology under development is therefore critical. Adaptations to the intervention are still possible in this stage, and barriers to implementation may be identified and eliminated. Early stage evaluations of eHealth may reveal hidden factors for successful implementation. To maximize the benefits associated with eHealth interventions while minimizing risks, evaluations of eHealth interventions should be performed during both design and deployment [70].

Heuristics are decision-making methods that may be applied when faced with short time frames and lack of resources with which to analyze complex data. Although heuristics may be helpful in many situations, the use may also lead to bias, as decisions made using a heuristic approach are likely to be suboptimal $[35,38]$. As such, to ensure the right eHealth solutions are adopted, increasing the pace of evaluations of eHealth solutions must not sacrifice the quality of scientific findings. Munafò et al [71] call for increased reproducible science and the need to implement measures to improve research efficiency and robustness of scientific findings. The authors argue for the adoption, evaluation, and ongoing improvement of measures to optimize the pace and efficiency of knowledge accumulation.

Evaluating eHealth technologies means evaluating the health care service as a whole. In other words, integration of eHealth interventions must be seen as part of a service and not as a standalone system. eHealth is designed to support the relationship between patients and their health care providers and will never replace the personal interaction between patient and provider [72]. This is why successful implementation requires a holistic approach including the technology, organizational structures, change management, economic feasibility, societal impacts, perceptions, user-friendliness, evaluation and evidence, legislation, policy, and governance [73].

Positive outcomes of any given technology implemented in health care will need to undergo upscaling to suit its intended use and maximize potential benefits. Wade et al [55] developed a qualitative framework for executing large-scale implementation of eHealth solutions. To produce an approach to implementation that ensures sustainable adoption in clinical environments, two key actions were highlighted: marketing of eHealth to patients, clinicians, and policy makers and establishing a practice community. Such leadership support may be vital to large-scale implementation. Policy makers also need awareness of how eHealth aligns with health care policies and how evidence of functionality may best be demonstrated to clinicians [55].

We found large diversity in the studies on the effect of eHealth. To influence policy makers' and clinicians' interpretation of outcomes, research is proposed to be dedicated to understanding optimal strategies for implementation [23,33]. Policy makers and local decision makers may need to adjust their expectations of immediate clinical or economic benefits of eHealth, as it is suggested that the greatest gains may be achieved for patients at highest risk of serious outcomes [47]. A summary of guidelines concerning user adaptations of eHealth solutions can be found in Table 3 .

\section{Comparison With Prior Work}

Through analysis of the relevant literature we identified several systematic reviews conducted by other research groups. While some of these studies addressed different stages of implementation, others highlighted specific factors of eHealth applications, patient subgroups, or diseases as their focus. Chi et al [56] focused on eHealth experience and innovative potential for patients' caregivers. While this study presented valuable insight into the application of eHealth, it did not provide a full picture of the subsequent effects of eHealth technology. Kitsiou et al [37] provided a broad overview by analyzing several systematic reviews but focused its efforts on patients with chronic heart failure.

Ekeland and Linstad [74] provided valuable insight to different models of eHealth governance but did not give insight into how different technologies may be received by their user groups. Schreiweis et al [75] studied enablers and barriers to eHealth implementation and presented similar conclusions as this study. The literature analysis presents expert discussions to emphasize their findings on enablers and barriers, while this study presents findings on evaluations methods applied in early assessment of eHealth. As such, this study explores the need for early evaluation to communicate the innovative potential in future eHealth research. Ross et al [19] studied eHealth implementation in a comprehensive review of reviews of eHealth and found that a frequent reason for unsuccessful implementation is that the information systems do not fit well with work practices or daily clinical work. Similar to this study, the authors also emphasize the need to focus on reflecting and evaluating the potential benefit of eHealth solutions. For software evaluations, the International Organization for Standardization/International Electrotechnical Commission (ISO/IEC) has defined evaluation methods for the quality of software products and provided common standards called the Systems and Software Quality Requirements and Evaluation series including ISO/IEC 25022:2016 and ISO/IEC 25023:2016 [76]. This quality evaluation framework focuses on metrics such as functional suitability, reliability, performance efficiency, usability, security, compatibility, maintainability, and portability, which are essential to ensure robust eHealth solutions. However, as emphasized above, integration of eHealth interventions must be seen as part of a service and not as a standalone system. As such, there is a need to establish an agreed upon evaluations 
framework to support eHealth solutions throughout the life cycle.

While the previous and related studies show similarities to this study, the focus of this study on the early development phase provides unique insight into factors important to consider when implementing eHealth solutions. Through exploring the early development phase and feasibility studies, this study seeks to provide the groundwork for applicable guidelines for early evaluation of eHealth solutions. As such, this scoping review may be applied as a roadmap to future studies.

\section{Limitations}

This scoping review may not have identified all published studies on the feasibility of eHealth, in particular the grey literature. The search strategy may have been compromised by nonstandardization of vocabulary in this relatively new field of research. As the literature search was conducted in two iterations, studies on the feasibility of eHealth may have been involuntarily excluded. As such, the representativeness of the selection of studies evaluating the feasibility of eHealth solutions may have been compromised. In addition, the attempt to draw out representative studies may have inadvertently caused this study to provide a small snapshot of the broad picture that is eHealth implementation. The results from a subset of this small scale may therefore be more fragile to potential outliers, changes in protocol, and new findings emerging in the coming years, as well as findings from the few years since the search was conducted in 2019. Using MeSH terms does not include non-MEDLINE indexed journals, which is a significant subset of PubMed-indexed papers. As such, JMIR Res Protoc or JMIR Formative Res publications were not included in this search, as they were not MEDLINE-indexed 2 years ago. This constitutes a major limitation to the search strategy in this paper. This scoping review did not include specific evaluation frameworks for eHealth components such as software quality but rather focused on evaluation of eHealth as an integrated part of a health system. Despite attempts to adjust the search strategy to several different terms previously used in the literature to describe similar methodologies, other terms may also exist. Although three comprehensive health databases were included in the search (PubMed, Ovid MEDLINE, and Cochrane), searching other databases may have included additional published studies. Our search included only studies in English, Norwegian, and Danish, although only English terms were used in the search. Furthermore, no consultations with stakeholders or experts were included in this review. Finally, although the method was systematically followed by the reviewers, each reviewer subjectively included studies based on the study criteria. Reviewer bias may have occurred in the attempt to include studies that represent a holistic view of eHealth solutions under development and testing. The classification and interpretation of the results were also subject to reviewer bias.

\section{Further Research}

As technology continually advances, so does the number of eHealth solutions. Additionally, its infusion into health services is emerging as an active area of research. This was seen in several studies in our literature search. The diversity of studies demonstrated that eHealth is a continually developing field. A large heterogeneity in methodology, sample, interventions, processes, and outcomes was found. It gives an overview of the current broad spectrum of methods but also reflects the broad eHealth scope: to improve health care and enhance quality of care.

Patients also represent diversity, as each of us is different and solutions need to be tailored to the individual. It might also mean that for more robust conclusions to be drawn, improvement related to methodology and standardization is needed. Several studies in this review were not free of bias, reported lack of blinding and related outcomes to the Hawthorne effect. Before a standardized recommendation for methodology concerning assessment and implementation of eHealth can be finalized, more research is needed to systematically validate the methods used for evaluating and implementing eHealth technologies. However, while standardization of methods can achieve better streamlining of new technologies, it is important to keep in mind that diversity and innovation within methodologies can also lead to improvement of innovative methods. Standardization of methodology, with sequential adaptations to new practices, may be a suitable way to optimize eHealth implementation methods. One approach for determining best practice may be to conduct mini case studies on the different methods of implementation and potential subsequent merging methods.

\section{Conclusion}

In conclusion, eHealth interventions have considerable potential to improve lifestyle changes and adherence to treatment recommendations, at least in the short term. While apps may support patients with self-management and increased adherence to treatment recommendations, sensor technology may provide additional use and data generation in the health care sector. Virtual reality has a role as a tool to support patient engagement, as well as providing a social platform for isolated patients. The use of television as a medium for system design may help alleviate barriers to user friendliness, as it has been a common household accessory for a long time. However, individualization, data management, and user-friendliness are important factors for use, and technical challenges need to be overcome for full integration to succeed. In terms of providing guidelines for evaluation at different stages of implementation, we found that usability, data management, and scaling strategies should be enhanced in early stage evaluations of future eHealth solutions. Evaluating an eHealth solution still under development may provide continuous information on the performance of the intervention in different development and pilot stages. As such, ineffective solutions may be rejected at an early stage, making room for innovations that provide the most benefit for society. The wide variation in interventions and methodology makes comparison of the results challenging and calls for standardization of methods. A stepwise approach by using subgroup analysis may be one solution that may allow us to understand patient characteristics, behavior, needs, and preferences, allowing us to tailor interventions to those patterns and achieve improved health outcomes while reducing costs. Follow-up, long-term interventions, and analysis of cost-effectiveness need to be included in future research. 
eHealth has the potential for refinement and personalization of existing health care practices and may be of great value. However, user involvement, training, and scaling strategies are important features to implement from the initiation of the development process.

\section{Acknowledgments}

The authors thank the staff at the Medical Library at Oslo University Hospital. The search strategy used and analyzed during this research is available from the corresponding author on reasonable request. All available data can be obtained by contacting the corresponding author. All authors meet the International Committee of Medical Journal Editors criteria for authorship. This submission will be funded through the Norwegian Research Council grant 237766/O30. This funding has enabled design of the stud; collection, analysis, and interpretation of data; and writing the manuscript.

\section{Authors' Contributions}

LNS and CRW conceived and designed the study. LNS and CRW analyzed the data. LNS authored the manuscript. KJK critically reviewed the manuscript.

\section{Conflicts of Interest}

None declared.

\section{Multimedia Appendix 1}

Search strategy Ovid MEDLINE.

[DOC File, 30 KB-Multimedia Appendix 1]

\section{References}

1. Health expenditure. Organisation for Economic Co-operation and Development. URL: https://www.oecd.org/health/ health-expenditure.htm [accessed 2021-04-21]

2. Van Velthoven MH, Cordon C. Sustainable adoption of digital health innovations: perspectives from a stakeholder workshop. J Med Internet Res 2019 Mar 25;21(3):e11922 [FREE Full text] [doi: 10.2196/11922] [Medline: 30907734]

3. Koskinen S, Puska P. From social determinants to reducing health inequalities. Int J Public Health 2009;54(2):53-54. [doi: 10.1007/s00038-009-7069-x] [Medline: 19288289]

4. Frank E, Pong J, Asher Y, Soares CN. Smart phone technologies and ecological momentary data: is this the way forward on depression management and research? Curr Opin Psychiatry 2018 Jan;31(1):3-6. [doi: 10.1097/YCO.0000000000000382] [Medline: 29084010]

5. Mehl G, Labrique A. Prioritizing integrated mHealth strategies for universal health coverage. Science 2014 Sep 12;345(6202):1284-1287. [doi: 10.1126/science.1258926] [Medline: 25214614]

6. Brearley L, Marten R, O'Connell TS. Universal Health Coverage: a commitment to close the gap. Rockefeller Foundation, Save the Children, the United Nations Children's Fund (UNICEF) and the World Health Organization. 2013. URL: https:/ /www.rockefellerfoundation.org/wp-content/uploads/uhc-close-the-gap-report.pdf [accessed 2021-04-21]

7. Vågerö D. Closing the global health gaps in a generation: how is it possible? Int J Public Health 2008;53(6):279-280. [doi: 10.1007/s00038-008-8140-8] [Medline: 19112589]

8. Mahler H. The meaning of "Health for All by the Year 2000". Am J Public Health 2016 Jan;106(1):36-38. [doi: 10.2105/AJPH.2016.106136] [Medline: 26696287]

9. Su D, Zhou J, Kelley MS, Michaud TL, Siahpush M, Kim J, et al. Does telemedicine improve treatment outcomes for diabetes? A meta-analysis of results from 55 randomized controlled trials. Diabetes Res Clin Pract 2016 Jun;116:136-148. [doi: 10.1016/j.diabres.2016.04.019] [Medline: 27321329]

10. Thimbleby H. Technology and the future of healthcare. J Public Health Res 2013 Dec 01;2(3):e28 [FREE Full text] [doi: 10.4081/jphr.2013.e28] [Medline: 25170499]

11. Koskinen S, Puska P. From social determinants to reducing health inequalities. Int J Public Health 2009;54(2):53-54. [doi: 10.1007/s00038-009-7069-x] [Medline: 19288289]

12. Arlati S, Colombo V, Spoladore D, Greci L, Pedroli E, Serino S, et al. A social virtual reality-based application for the physical and cognitive training of the elderly at home. Sensors (Basel) 2019 Jan 10;19(2):1 [FREE Full text] [doi: 10.3390/s19020261] [Medline: 30634719]

13. Smith AC, Thomas E, Snoswell CL, Haydon H, Mehrotra A, Clemensen J, et al. Telehealth for global emergencies: implications for coronavirus disease 2019 (COVID-19). J Telemed Telecare 2020 Mar 20:1357633X20916567. [doi: 10.1177/1357633X20916567] [Medline: 32196391]

14. Ohannessian R, Duong TA, Odone A. Global telemedicine implementation and integration within health systems to fight the COVID-19 pandemic: a call to action. JMIR Public Health Surveill 2020 Apr 02;6(2):e18810 [FREE Full text] [doi: 10.2196/18810] [Medline: $\underline{\text { 32238336] }}$ 
15. Coughlin JF, Pope JE, Leedle BR. Old age, new technology, and future innovations in disease management and home health care. Home Health Care Manag Pract 2016 Jun 30;18(3):196-207. [doi: 10.1177/1084822305281955]

16. Brown MM, Brown GC, Sharma S, Landy J. Health care economic analyses and value-based medicine. Surv Ophthalmol 2003;48(2):204-223. [doi: 10.1016/s0039-6257(02)00457-5] [Medline: 12686305]

17. Fourneyron E, Wittwer J, Rachid Salmi L, Groupe de recherche Eva TSN. [Health information technology: current use and challenges for primary healthcare services]. Med Sci (Paris) 2018;34(6-7):581-586 [FREE Full text] [doi: 10.1051/medsci/20183406000] [Medline: 30067214]

18. Vehko T, Hyppönen H, Puttonen S, Kujala S, Ketola E, Tuukkanen J, et al. Experienced time pressure and stress: electronic health records usability and information technology competence play a role. BMC Med Inform Decis Mak 2019 Aug 14;19(1):160 [FREE Full text] [doi: 10.1186/s12911-019-0891-z] [Medline: 31412859]

19. Ross J, Stevenson F, Lau R, Murray E. Factors that influence the implementation of e-health: a systematic review of systematic reviews (an update). Implement Sci 2016 Oct 26;11(1):146 [FREE Full text] [doi: 10.1186/s13012-016-0510-7] [Medline: 27782832]

20. Tsiknakis M, Kouroubali A. Organizational factors affecting successful adoption of innovative eHealth services: a case study employing the FITT framework. Int J Med Inform 2009 Jan;78(1):39-52. [doi: 10.1016/j.ijmedinf.2008.07.001] [Medline: 18723389]

21. Tsasis P, Wu J, An A, Wong HJ, An X, Mei Z, et al. Conceptualizing type 2 diabetes and its management. J Multidiscip Healthc 2016;9:133-136 [ [FREE Full text] [doi: 10.2147/JMDH.S88684] [Medline: 27099510]

22. Black AD, Car J, Pagliari C, Anandan C, Cresswell K, Bokun T, et al. The impact of eHealth on the quality and safety of health care: a systematic overview. PLoS Med 2011 Jan;8(1):e1000387 [FREE Full text] [doi: 10.1371/journal.pmed.1000387] [Medline: 21267058]

23. Petersen C, Adams SA, DeMuro PR. mHealth: don't forget all the stakeholders in the business case. Med 202015 Dec 31;4(2):e4 [FREE Full text] [doi: 10.2196/med20.4349] [Medline: 26720310]

24. Varsi C, Solberg Nes L, Kristjansdottir OB, Kelders SM, Stenberg U, Zangi HA, et al. Implementation strategies to enhance the implementation of ehealth programs for patients with chronic illnesses: realist systematic review. J Med Internet Res 2019 Sep 27;21(9):e14255 [FREE Full text] [doi: 10.2196/14255] [Medline: $\underline{\text { 31573934] }}$

25. Bradway M, Gabarron E, Johansen M, Zanaboni P, Jardim P, Joakimsen R, et al. Methods and measures used to evaluate patient-operated mobile health interventions: scoping literature review. JMIR Mhealth Uhealth 2020 Apr 30;8(4):e16814 [FREE Full text] [doi: 10.2196/16814] [Medline: 32352394]

26. Fernandez ME, Ten Hoor GA, van Lieshout S, Rodriguez SA, Beidas RS, Parcel G, et al. Implementation mapping: using intervention mapping to develop implementation strategies. Front Public Health 2019;7:158 [FREE Full text] [doi: 10.3389/fpubh.2019.00158] [Medline: $\underline{31275915]}$

27. Støme LN, Moger T, Kidholm K, Kværner KJ. A web-based communication platform to improve home care services in Norway (DigiHelse): pilot study. JMIR Form Res 2020 Jan 20;4(1):e14780 [FREE Full text] [doi: 10.2196/14780] [Medline: $\underline{31958062]}$

28. Moher D, Liberati A, Tetzlaff J, Altman DG. Preferred reporting items for systematic reviews and meta-analyses: the PRISMA statement. PLoS Med 2009 Jul 21;6(7):e1000097 [FREE Full text] [doi: 10.1371/journal.pmed.1000097] [Medline: $\underline{19621072]}$

29. Noncommunicable diseases. Geneva: World Health Organization; 2018. URL: https://www.who.int/en/news-room/fact-sheets/ detail/noncommunicable-diseases [accessed 2021-04-21]

30. Støme LN, Moger T, Kidholm K, Kværner KJ. Early assessment of innovation in a healthcare setting. Int J Technol Assess Health Care 2019 Jan;35(1):17-26. [doi: 10.1017/S0266462318003719] [Medline: 30744712 ]

31. Ding H, Moodley Y, Kanagasingam Y, Karunanithi M. A mobile-health system to manage chronic obstructive pulmonary disease patients at home. Conf Proc IEEE Eng Med Biol Soc 2012;2012:2178-2181. [doi: 10.1109/EMBC.2012.6346393] [Medline: 23366354]

32. Fitzsimmons DA, Thompson J, Bentley CL, Mountain GA. Comparison of patient perceptions of telehealth-supported and specialist nursing interventions for early stage COPD: a qualitative study. BMC Health Serv Res 2016 Aug 22;16(1):420 [FREE Full text] [doi: 10.1186/s12913-016-1623-z] [Medline: 27549751]

33. Hui CY, Walton R, McKinstry B, Jackson T, Parker R, Pinnock H. The use of mobile applications to support self-management for people with asthma: a systematic review of controlled studies to identify features associated with clinical effectiveness and adherence. J Am Med Inform Assoc 2017 May 01;24(3):619-632. [doi: 10.1093/jamia/ocw143] [Medline: 27694279]

34. Kamei T, Yamamoto Y, Kajii F, Nakayama Y, Kawakami C. Systematic review and meta-analysis of studies involving telehome monitoring-based telenursing for patients with chronic obstructive pulmonary disease. Jpn J Nurs Sci 2013 Dec;10(2):180-192. [doi: 10.1111/j.1742-7924.2012.00228.x] [Medline: 24373441]

35. Lilholt PH, Jensen MH, Hejlesen OK. Heuristic evaluation of a telehealth system from the Danish TeleCare North Trial. Int J Med Inform 2015 May;84(5):319-326. [doi: 10.1016/j.ijmedinf.2015.01.012] [Medline: 25666638]

36. Burridge JH, Lee ACW, Turk R, Stokes M, Whitall J, Vaidyanathan R, et al. Telehealth, wearable sensors, and the internet: will they improve stroke outcomes through increased intensity of therapy, motivation, and adherence to rehabilitation 
programs? J Neurol Phys Ther 2017 Jul;41 Suppl 3 Supplement, IV STEP Special Issue:S32-S38. [doi: 10.1097/NPT.0000000000000183] [Medline: 28628594]

37. Kitsiou S, Paré G, Jaana M. Effects of home telemonitoring interventions on patients with chronic heart failure: an overview of systematic reviews. J Med Internet Res 2015;17(3):e63 [FREE Full text] [doi: 10.2196/jmir.4174] [Medline: 25768664]

38. Monkman H, Griffith J, Kushniruk AW. Evidence-based heuristics for evaluating demands on ehealth literacy and usability in a mobile consumer health application. Stud Health Technol Inform 2015;216:358-362. [Medline: 26262071]

39. Georgsson M, Staggers N. Patients' perceptions and experiences of a mhealth diabetes self-management system. Comput Inform Nurs 2017 Mar;35(3):122-130. [doi: 10.1097/CIN.0000000000000296] [Medline: 27748662]

40. Van Hoecke S, Steurbaut K, Taveirne K, De Turck F, Dhoedt B. Design and implementation of a secure and user-friendly broker platform supporting the end-to-end provisioning of e-homecare services. J Telemed Telecare 2010;16(1):42-47. [doi: 10.1258/jtt.2009.001011] [Medline: 20086267]

41. Abd Sukor J, Mohktar MS, Redmond SJ, Lovell NH. Signal quality measures on pulse oximetry and blood pressure signals acquired from self-measurement in a home environment. IEEE J Biomed Health Inform 2015 Jan;19(1):102-108. [doi: 10.1109/JBHI.2014.2361654] [Medline: 25312963]

42. Angius G, Pani D, Raffo L, Randaccio P, Seruis S. A tele-home care system exploiting the DVB-T technology and MHP. Methods Inf Med 2008;47(3):223-228. [doi: 10.3414/me9114] [Medline: 18473088]

43. Arlati S, Colombo V, Spoladore D, Greci L, Pedroli E, Serino S, et al. A social virtual reality-based application for the physical and cognitive training of the elderly at home. Sensors (Basel) 2019 Jan 10;19(2):1 [FREE Full text] [doi: 10.3390/s19020261] [Medline: 30634719]

44. Bartels SJ, DiMilia PR, Fortuna KL, Naslund JA. Integrated care for older adults with serious mental illness and medical comorbidity: evidence-based models and future research directions. Psychiatr Clin North Am 2018 Mar;41(1):153-164 [FREE Full text] [doi: 10.1016/j.psc.2017.10.012] [Medline: 29412843]

45. Cai H, Toft E, Hejlesen O, Hansen J, Oestergaard C, Dinesen B. Health professionals' user experience of the intelligent bed in patients' homes. Int J Technol Assess Health Care 2015 Jan;31(4):256-263. [doi: 10.1017/S0266462315000380] [Medline: 26292761]

46. Mora N, Matrella G, Ciampolini P. Cloud-based behavioral monitoring in smart homes. Sensors (Basel) 2018 Jun 15;18(6):15 [FREE Full text] [doi: 10.3390/s18061951] [Medline: 29914127]

47. Norman GJ, Orton K, Wade A, Morris AM, Slaboda JC. Operation and challenges of home-based medical practices in the US: findings from six aggregated case studies. BMC Health Serv Res 2018 Jan 27;18(1):45 [FREE Full text] [doi: 10.1186/s12913-018-2855-x] [Medline: 29374478]

48. Weiner E, Trangenstein P, McNew R, Gordon J. Using the virtual reality world of second life to promote patient engagement. Stud Health Technol Inform 2016;225:198-202 [FREE Full text] [Medline: 27332190]

49. Aguilar KM, Campbell RS, Fiester A, Simpson RL, Hertel C. Bringing care home: how telemonitoring can expand population health management beyond the hospital. Nurs Adm Q 2014;38(2):166-172. [doi: 10.1097/NAQ.0000000000000029] [Medline: 24569764]

50. Burkow TM, Vognild LK, Krogstad T, Borch N, Ostengen G, Bratvold A, et al. An easy to use and affordable home-based personal eHealth system for chronic disease management based on free open source software. Stud Health Technol Inform 2008;136:83-88. [Medline: 18487712]

51. McLean S, Sheikh A, Cresswell K, Nurmatov U, Mukherjee M, Hemmi A, et al. The impact of telehealthcare on the quality and safety of care: a systematic overview. PLoS One 2013;8(8):e71238 [FREE Full text] [doi: 10.1371/journal.pone.0071238] [Medline: 23977001]

52. Sanders C, Rogers A, Bowen R, Bower P, Hirani S, Cartwright M, et al. Exploring barriers to participation and adoption of telehealth and telecare within the Whole System Demonstrator trial: a qualitative study. BMC Health Serv Res 2012;12:220 [FREE Full text] [doi: 10.1186/1472-6963-12-220] [Medline: 22834978]

53. Simon SK, Seldon HL. Personal health records: mobile biosensors and smartphones for developing countries. Stud Health Technol Inform 2012;182:125-132. [Medline: 23138087]

54. Tschanz M, Dorner TL, Denecke K. eMedication meets ehealth with the electronic medication management assistant (eMMA). Stud Health Technol Inform 2017;236:196-203. [Medline: 28508796]

55. Wade VA, Taylor AD, Kidd MR, Carati C. Transitioning a home telehealth project into a sustainable, large-scale service: a qualitative study. BMC Health Serv Res 2016 May 16;16:183 [FREE Full text] [doi: 10.1186/s12913-016-1436-0] [Medline: 27185041]

56. Chi N, Demiris G. A systematic review of telehealth tools and interventions to support family caregivers. J Telemed Telecare 2015 Jan;21(1):37-44 [FREE Full text] [doi: 10.1177/1357633X14562734] [Medline: 25475220]

57. Mantas G, Lymberopoulos D, Komninos N. Integrity mechanism for eHealth tele-monitoring system in smart home environment. Annu Int Conf IEEE Eng Med Biol Soc 2009;2009:3509-3512. [doi: 10.1109/IEMBS.2009.5334524] [Medline: 19964802]

58. McLean S, Nurmatov U, Liu JLY, Pagliari C, Car J, Sheikh A. Telehealthcare for chronic obstructive pulmonary disease: Cochrane Review and meta-analysis. Br J Gen Pract 2012 Nov;62(604):e739-e749 [FREE Full text] [doi:

10.3399/bjgp12X658269] [Medline: 23211177] 
59. Bevan N. International Standards for HCI. In: Encyclopedia of Human Computer Interaction. Hershey: IGI Global; $2006: 15$.

60. Garvelink MM, Agbadjé TT, Freitas A, Bergeron L, Petitjean T, Dugas M, et al. Improving a web-based tool to support older adults to stay independent at home: qualitative study. JMIR Mhealth Uhealth 2020 Jul 22;8(7):e16979 [FREE Full text] [doi: 10.2196/16979] [Medline: 32412908]

61. People-centred health care. Geneva: World Health Organization URL: https://www.who.int/servicedeliverysafety/areas/ people-centred-care/en/ [accessed 2021-04-21]

62. Ghazali M, Ariffin N. User centered design practices in healthcare: a systematic review. 2014 Presented at: 3rd International Conference on User Science and Engineering (i-USEr); 2014; Shah Alam. [doi: 10.1109/iuser.2014.7002683]

63. Michie S, Yardley L, West R, Patrick K, Greaves F. Developing and evaluating digital interventions to promote behavior change in health and health care: recommendations resulting from an international workshop. J Med Internet Res 2017 Jun 29;19(6):e232 [FREE Full text] [doi: 10.2196/jmir.7126] [Medline: 28663162]

64. Esposito D, Taylor EF, Gold M. Using qualitative and quantitative methods to evaluate small-scale disease management pilot programs. Popul Health Manag 2009 Feb;12(1):3-15. [doi: 10.1089/pop.2008.0037] [Medline: 19216674]

65. Aguilar KM, Campbell RS, Fiester A, Simpson RL, Hertel C. Bringing care home: how telemonitoring can expand population health management beyond the hospital. Nurs Adm Q 2014;38(2):166-172. [doi: 10.1097/NAQ.0000000000000029] [Medline: 24569764]

66. Ryan P, Sawin KJ. The individual and family self-management theory: background and perspectives on context, process, and outcomes. Nurs Outlook 2009;57(4):217-225 [FREE Full text] [doi: 10.1016/j.outlook.2008.10.004] [Medline: 19631064]

67. Dineen-Griffin S, Garcia-Cardenas V, Williams K, Benrimoj SI. Helping patients help themselves: a systematic review of self-management support strategies in primary health care practice. PLoS One 2019;14(8):e0220116 [FREE Full text] [doi: 10.1371/journal.pone.0220116] [Medline: 31369582]

68. Gellis ZD, Kenaley B, McGinty J, Bardelli E, Davitt J, Ten HT. Outcomes of a telehealth intervention for homebound older adults with heart or chronic respiratory failure: a randomized controlled trial. Gerontologist 2012 Aug;52(4):541-552. [doi: 10.1093/geront/gnr134] [Medline: 22241810]

69. Wicks P, Stamford J, Grootenhuis MA, Haverman L, Ahmed S. Innovations in e-health. Qual Life Res 2014 Feb;23(1):195-203 [FREE Full text] [doi: 10.1007/s11136-013-0458-x] [Medline: 23852096]

70. Catwell L, Sheikh A. Evaluating eHealth interventions: the need for continuous systemic evaluation. PLoS Med 2009 Aug;6(8):e1000126 [FREE Full text] [doi: 10.1371/journal.pmed.1000126] [Medline: 19688038]

71. Munafò MR, Nosek BA, Bishop DVM, Button KS, Chambers CD, Percie du Sert N, et al. A manifesto for reproducible science. Nat Hum Behav 2017 Jan 10;1(1):0021 [FREE Full text] [doi: 10.1038/s41562-016-0021]

72. Harrison JP, Lee A. The role of e-Health in the changng health care environment. Nurs Econ 2006;24(6):283-288. [Medline: 17266004]

73. van Dyk L. A review of telehealth service implementation frameworks. Int J Environ Res Public Health 2014 Jan 23;11(2):1279-1298 [FREE Full text] [doi: 10.3390/ijerph110201279] [Medline: 24464237]

74. Ekeland AG, Linstad LH. Elaborating models of ehealth governance: qualitative systematic review. J Med Internet Res 2020 Oct 28;22(10):e17214 [FREE Full text] [doi: 10.2196/17214] [Medline: $\underline{33112247]}$

75. Schreiweis B, Pobiruchin M, Strotbaum V, Suleder J, Wiesner M, Bergh B. Barriers and facilitators to the implementation of ehealth services: systematic literature analysis. J Med Internet Res 2019 Nov 22;21(11):e14197 [FREE Full text] [doi: 10.2196/14197] [Medline: $\underline{31755869]}$

76. Nakai H, Tsuda N, Honda K, Washizaki H, Fukazawa Y. A SQuaRE-based software quality evaluation framework and its case study. 2016 Presented at: IEEE Region 10 Conference (TENCON); 2016; Singapore URL: https://doi.org/10.1109/ TENCON.2016.7848750

\section{Abbreviations}

COPD: chronic obstructive pulmonary disease

IEC: International Electrotechnical Commission

ISO: International Organization for Standardization

PRISMA: Preferred Reporting Items for Systematic Reviews and Meta-analyses 
Edited by G Eysenbach; submitted 12.06.20; peer-reviewed by MDG Pimentel, M Kolotylo-Kulkarni, M Rauws, J Li, A Adly, A Adly,

M Adly; comments to author 22.07.20; revised version received 15.09.20; accepted 13.04.21; published 30.04.21

Please cite as:

Støme LN, Wilhelmsen CR, Kvarner KJ

Enabling Guidelines for the Adoption of eHealth Solutions: Scoping Review

JMIR Form Res 2021;5(4):e21357

URL: https://formative.jmir.org/2021/4/e21357

doi: $10.2196 / 21357$

PMID:

CLinn Nathalie Støme, Christian Ringnes Wilhelmsen, Kari Jorunn Kværner. Originally published in JMIR Formative Research (https://formative.jmir.org), 30.04.2021. This is an open-access article distributed under the terms of the Creative Commons Attribution License (https://creativecommons.org/licenses/by/4.0/), which permits unrestricted use, distribution, and reproduction in any medium, provided the original work, first published in JMIR Formative Research, is properly cited. The complete bibliographic information, a link to the original publication on https://formative.jmir.org, as well as this copyright and license information must be included. 